\title{
PARQUES INFANTIS DE MÁRIO DE ANDRADE
}

Elizabeth Abdanur*

Mário de Andrade nos deixou obra de singular grandeza, como escritor, poeta, etnografo, crftico de música, de literatura, de artes plásticas etc. Entre tanta coisa que realizou e tantos projetos que ainda ficaram por realizar, sabemos que houve um desenvolvido no Departamento Municipal de Cultura da Prefeitura de Sāo Paulo, entre os anos de 1935 e 1938. Mário de Andrade, além de autor do projeto de criaçáo desse Departamento, foi também seu primeiro diretor, dedicando a ele tres anos e meio de intenso trabalho. Esta $\hat{\epsilon}$, sem dúvida, razão suficiente para que voltemos um pouco de nossa atençăo para o Departamento Municipal de Cultura da cidade de São Paulo nos anos em que esteve sob a direção de Mário de Andrade. Muitos de seus preceitos para o desenvolvimento da "cultura brasileira" - uma de suas grandes preocupaçōes - ficaram ali caracterizados de maneira substantiva.

Na trajetória de Mário de Andrade, os trabalhos no Departamento de Cultura coincidem com o projeto do Serviço do Património Histórico e Artístico Nacional (SPHAN) realizado por ele e Rodrigo Melo Franco de Andrade sob encomenda do entáo Ministro da Educação e Cultura, Gustavo Capanema. Naquele momento de sua vida, Mário de Andrade se dizia profundamente preocupado em dar maior "funcionalidade prática" a sua arte. Nesse sentido, é provável que o Departamento de Cultura e o SPHAN tenham contribufdo em grande parte para a avaliação que o artista faz de sua obra anos depois:

"Náo tenho a mínima reserva em afirmar que toda a minha obra representa uma dedicaçáo feliz a problemas do meu tempo e minha terra. Ajudei coisas, maquinei coisas, fiz coisas, muita coisa!

- Professora na UNICAMP 
"Abandonei, traiçáo conșciente, a ficçáo em favor de um homem-de-estudo que fundamentalmente não sou. Mas e que eu decidira impregnar tudo quanto fazia de um valor utilitário, um valor prático de vida, que fosse alguma coisa mais terrestre que ficçá, prazer estético, a beleza divina." (1)

Essas foram as razóes que levaram Mário de Andrade a Prefeitura de Sáo Paulo, o entendimento de que deveria se dedicar aos "problemas de seu tempo" e conferir a sua arte um "valor utilitário". E entre os problemas de sua época, enfatizou o desprezo à cuitura, especialmente o descuido para com a educaçáo do povo. Sem condenar ou mesmo questionar o elitismo na cultura e na educaçá, a enorme desigualdade de condiçoes entre "elite" e "povo" no acesso aos bens culturais era para ele inaceitável. E Mário atribuiu aos governos a responsabilidade pela elevaçáo cultural do povo. São afirmaçóes que encontramos na carta ao amigo Paulo Duarte, escrita no momento em que o Departamento de Cultura e o SPHAN eram suas maiores preocupaços:

"Num pais como o nosso, em que a cultura infelizmente ainda náo é uma necessidade quotidiana de ser, está se aguçando com violencia dolorosa o contraste entre uma pequena elite que realmente se cultiva e um povo abichornado em seu rude corpo. Há que forçar um maior entendimento mutuo, um maior nivelamento geral de cultura que, sem destruir a elite, a torne mais acessivel a todos, e em consequencia the de uma validade verdadeiramente funcional. Está claro, pois, que o nivelamento náo poderá consistir em cortar o tope ensolarado das elites, mas em provocar com atividade o erguimento das partes que estáo na sobra, pondo-as em condiçáo de receber mais luz. Tarefa que compete aos governos."

Mas a convicçáo de Mário de Andrade de que naquele momento deveria sacrificar a ficçăo por algo mais "útil" à vida de todos nāo impediu que o envolvimento com o Departamento de Cultura fosse vivenciado por ele em meio a grandes conflitos pessoais. Mário se entregou de maneira profunda ao trabalho, sem no entanto estar muito certo de que teria feito a melhor escolha. É provável que suas dificuldades em lidar com o mundo da polftica conferissem a seus confitos uma dimensão maior. Logo que iniciou os trabalhos no Departamento de Cultura, Mário escreveu a Murilo Miranda contando o impasse em que vivia: 1 ANDRADE, Mário de. O Movimento Modernista. In: Aspectas da literotura brasileina 5
ed. Sto Paulo, Martins, 1974. p. 252 e 254 .

2 Idem. Carta a Paulo Duarte, SAo Paulo, 1937. In: DUARTE, Paulo. Mario de Andrade por ele mesmo, 2 ed. S6o Paulo, Hucitec/Prefeitura de Sאo Paulo, 1985. p. 150-1. 
"Năo faço projetos, deixei o que tinha comigo pra mais tarde (ou quem sabe nunca?...), estou cheio, trabalhando com paixáo, com violenta paixăo, nesta primeira vida minha em que tomo contato burocrático com o povo $e$ com a vida. Não recuso que a burocracia e este contato novo săo horrlveis, e experiencias ferozes pra mim, mas é a vida!(...) Positivamente năo estou alegre, e é certo que ainda năo reachei a minha felicidade perdida neste posto novo. Se náo conseguir reencontrá-la no cargo, deixo o cargo" (3).

Mas năo deixou. Mário de Andrade permaneceu no cargo até que as mudanças na Prefeitura de São Paulo, após o golpe do Estado Novo tornassem impossivel sua sustentaçáo como diretor do Departa. mento de Cultura. Porque, mesmo com todos os conflitos que viveu a partir do momento em que aceitou um cargo público como aquele, fez dos primeiros anos de existéncia do Departamento de Cultura o tempo em que a Prefeitura de Săo Paulo póde realizar um extenso e complexo programa de ação cultural para a cidade.

A preocupaçăo de Mário de Andrade em se tornar um artista mais útil socialmente nāo foi uma preocupaçăo isolada naquele momento. Nos anos trinta, o engajamento de intelectuais em programas do governo foi intenso em todo o pais. Em Săo Paulo a situaçăo não era diferente, mas também teve suas peculiaridades.

As elites paulistas, principalmente os grupos organizados em torno do Partido Democrático, vinham desde os anos vinte elegendo a educação e a cultura como os alicerces de uma ordem social estável. Esta estratégia politica marcou o governo de Armando de Salles Oliveira nos anos trinta. Salles Oliveira foi indicado por Getúlio Vargas para interventor federal em São Paulo em agosto de 1933. A escolha resultou do novo arranjo das relaçōes entre Såo Paulo e o governo federal depois da derrota do movimento de 1932, quando as elites paulistas, com apoio da população, procuraram derrubar o governo provisório de Getúlio Vargas para devolver a Sáo Paulo o comando do país.

A criaçáo do Departamento Municipal de Cultura é um dos desdobramentos do projeto político do governo de Armando de Salles Oliveira, cuja expressăo máxima foi a criaçăo da Universidade de Săo Paulo em janeiro de 1934. Já em maio de 1933, as elites paulistas se uniram em torno de um projeto cultural entăo idealizado como principal estratégia política e fundaram a Escola Livre de Sociologia e Política. À Escola caberia formar os técnicos e administradores públicos para o aperfeiçoamento do governo paulista. À nova Universidade caberia formar as "elites intelectuais" - para usar as palavras do jorna-

3 Carta de Mário de Andrade a Murilo Miranda, São Paulo, 6 de julho de 1935. In: ANDRADE, Mário de. Cartas a Murilo Miranda (1934-1945). Rio de Janciro, Nova Fronteira, 1981. p. 18. 
lista Júlio de Mesquita Filho - encarregadas de organizar o sistema educacional e orientar as elites dirigentes (4). Ao Departamento Municipal de Cultura caberia basicamente promover o aprimoramento cultural do povo. Assim, as funçós das trés instituiçסes se complementariam para o alcance do objetivo maior das elites paulistas. Para elas, a questăo fundamental era recuperar a força e o prestígio político de São Paulo atraves da constituiçăo de um governo capaz de controlar com maior eficiencia os problemas sociais e ao mesmo tempo combater o comunismo.

Armando de Salles Oliveira nomeou prefeito de Sáo Paulo o engenheiro industrial Fábio da Silva Prado, com quem mantinha relaçóes políticas há alguns anos. Fábio Prado tomou posse em setembro de 1934. Levou com ele, para a Prefeitura de São Paulo, o jornalista Paulo Duarte como chefe de gabinete. Paulo Duarte fora um dos fundadores do Partido Democrático de Sáo Paulo em 1926, e redatorchefe do Diário Nacional. Na Prefeitura, tornou-se o responsável pela reforma administrativa implementada por Fábio Prado que incluiu, entre várias mudanças, a criaçáo de um novo Departamento Munici-pal, o Departamento de Cultura.

Nos anos vinte, o Partido Democrático havia criado a convivencia entre políticos e alguns jovens artistas e intelectuais ligados ao movimento modernista do infcio da década. Naquele momento, Paulo Duarte se aproximara de Mário de Andrade, Sérgio Milliet e Rubens Borba de Moraes. Quando foi para a Prefeitura de Sáo Paulo, pediu a Mário que elaborasse o projeto do Departamento de Cultura, sugerido por ele proprio ao Prefeito Fábio Prado. No dia 30 de maio de 1935, o Diário Oficial publicou o Ato n9 861 do Prefeito de Sáo Paulo criando o Departamento Municipal de Cultura e de Recreaçáo, assim chamado inicialmente. No dia seguinte, Mário de Andrade foi nomeado diretor e chefe da Divisåo de Expansáo Cultural do novo Departamento que teria por finalidades gerais:

" - estimular e desenvolver todas as iniciativas destinadas a favorecer o movimento educacional, artístico e cultural;

- (...) cooperar em um conjunto sistemático de medidas, para o desenvolvimento da arte dramática, (...) da música, do canto, do teatro e do cinema;

- por ao alcance de todos, pelos serviços de uma estaçăo radio-difusora, palestras e cursos populares de organizaçăo literária ou cientifica, (...) tudo o que possa contribuir para o aperfeiçoamento e extensão da cultura;

4 Sobre a USP, ver CARDOSO, Irene, A Universidade da commoño paulista SGo Paulo,
Autores Assoctados/Editora Cortez, 1982 
- criar e organizar bibliotecas públicas (...) para a difusăo da cultura em todas as camadas da populaçăo;

- organizar (...) parques infantis, campos de atletismo, piscina e o estádio da cidade (...);

- recolher, colecionar, restaurar e publicar documentos antigos, material e dados históricos e sociais, que facilitem as pesquisas e estudos sobre a história da cidade de Såo Paulo(...)." (5)

A Biblioteca, o Arquivo e o Teatro Municipal, existentes em Sáo Paulo antes da criaçáo do Departamento de Cultura, foram a ele incorporados e serviram de ponto de partida para a concretizaçăo dos objetivos anunciados na legislaçáo. Rubens Borba de Moraes, entáo chefe da Divisão de Bibliotecas, trouxe para Sáo Paulo a novidade da biblioteca circulante, um caminhāo carregado de livros que estacionava em praças ou jardins da cidade possibilitando a quem ali estivesse algumas horas de leitura ao ar livre. Os planos inclufam também a criaçao das' bibliotecas de bairro e até bibliotecas de fábricas. Borba de Moraes promoveu uma política voltada para a aquisiçăo de coleçōes importantes e a atualizaçăo do acervo da Biblioteca Municipal, além da modernizaçăo dos serviços bibliotecários através da organizaçăo do primeiro curso de Biblioteconomia do país.

No Arquìvo Municipal, Sérgio Milliet organizou programas de pesquisas sociais sobre a cidade; investiu na organizaçăo e recuperaçăo dos documentos históricos ali preservados e transformou a tímida $R e$ vista do Arquivo Municipal em uma das principais publicaçōes brasileiras na área de Ciencias Humanas. Ali colaboraram, com artigos, Claude e Dina Lévi-Strauss, Pierre Monbeig, Artur Ramos, Plínio Airosa e vários outros intelectuais representativos da época.

Na Divisáo de Expansão Cultural, Mário de Andrade criou a Discoteca Pública Municipal, organizou um curso de Etnografia, promoveu concertos semanais gratuitos no Teatro Municipal, criou a Orquestra Municipal, o Coral Paulistano, o Coral Popular, um trio, um quarteto, promoveu o Congresso da Lingua Nacional Cantada e a Missáo de Pesquisas Folclóricas. A Missáo foi seu último projeto no Departamento de Cultura. Podemos dizer que valeu como uma espécie de continuaçắo das atividades do "Turista Aprendiz", agora imbuídas de caráter oficial e cientifico. Os pesquisadores integrantes da Missăo passaram alguns meses no Nordeste documentando, através de filmes, fotografias, gravaçáo de discos etc., grande aúmero de manifestaçoes artísticas e culturais populares.

5 Leis e Decretas da Prefeitura Municipal de São Paulo, ano de 1935.

Rev. Inst. Est. Bras., SP, 36:263-270, 1994 
Os parques infantis do Departamento de Cultura constitufram um dos programas da Prefeitura de São Paulo em que a presença de Mário de Andrade foi mais marcante, apesar da criaçáo deles ter antecedido o próprio Departamento de Cultura. Como o Arquivo, a Biblioteca e o Teatro Municipal, o Serviço Municipal de Jogos e Recreio, responsável pelo programa de parques infantis, também foi incorporado ao Departamento de Cultura no momento em que este foi instituido.

Os parques infantis da Prefeitura de Sáo Paulo foram destinados a recreaçáo das crianças pobres da cidade, especialmente os filhos de operários. O primeiro a ser instalado foi o Parque Infantil Pedro II. Em seguida surgiram o Parque Infantil da Lapa e o do Ipiranga. Posteriormente, e por último, instalou-se o Parque Infantil de Santo Amaro. Ate 1938, ano da safda de Mário de Andrade do Departamento de Cultura, estes foram os únicos em funcionamento na cidade. Muitos outros porém já estavam projetados. Seriam instalados "todos em bairro de trabalho ou de pobreza, imediaçoes de escolas ou fábricas, enfim onde pudesse ser mais útil socialmente" (6). Além da recreaçăo orientada por educadores, essas crianças recebiam nos parques assistencia médica e dentária, educaçáo sanitária e higiencia, roupas e alimentação. O espaço físico dos parques foi assim descrito por Nicanor $\mathrm{Mi}$ randa, o responsável pela Divisăo de Educação e Recreio do Departamento de Cultura:

"Cada parque possui, no mínimo, um campo gramado, um
abrigo-mor, com salas de instrutores, sala de médico, chu-
veiros, instalaçoes sanitárias, além de dois galpoes late-
rais ao abrigo-mor. Várias espécies de aparelhos tais
como balanços, gangorras, passos gigantes, carrocéis, des-
lizadores, toros de equillbrio e outros estăo distribufdos
pelo campo, além de um tanque de vadiar e taboleiros de
areia." (7)

A frequencia aos parques era aberta em qualquer dia a qualquer criança. O preenchimento da ficha de inscriçăo da criança num dos parques da cidade também náo era obrigatória, era uma opçáo dos pais que desejassem um registro do desenvolvimento do filho quanto a altura, peso, doenças etc. Dados relativos ao número de crianças que frequentavam os parques de Sao Paulo mostram que cada parque recebia diariamente entre 300 e 400 crianças. Ali, brincavam, faziam ginástica, participavam de jogos e torneios, desenhavam, liam e aprendiam vários tipos de artesanato. $O$ cotidiano dos parques era bastante diferente do cotidiano escolar. Neles, as crianças encontravam uma estrutura menos rigida, onde elas proprias organizavam suas atividades:

6 DUARTE, Paulo. Mario de Andrade por ele mesno. Op. eih p. 82

7 Voz de Portugal. Rio de Janeiro, 14/02/1937. (Livro de Recortes de Jomais, Ano de 1937, da Seçáo de Obras Raras da Biblioteca Mário de Andrade). 
"Em cada parque existe uma biblioteca com cerca de 300 volumes, onde os bibliotecários sáo sempre crianças eleitas pelos companheiros (...). Cada parque possui também um jornalzinho, dirigido, redigido e ilustrado exclusivamente pelas crianças, e onde são publicados composiçoes, contos, versos, cartas enigmáticas e desenhos (...)." (8)

Benedito Junqueira Duarte, fotógrafo do Departamento de Cultura, registrou em 288 fotografias a vida das crianças nos parques que funcionaram em Sáo Paulo entre os anos de 1935 e 1938. Essas fotos documentam em detalhes a paisagem dos parques, as instalaçסes e os vários tipos de atividades nas quais as crianças se envolviam. As imagens de Benedito Duarte e suas respectivas legendas fixaram, por exemplo, momentos em que as crianças faziam exercicios fisicos: "Fila indígena; Preparativos para a ginástica; Ginástica com bastơes; Corrida; Ginástica em roda; Rumo ao sol e Banho de Sol".

Jogos e brincadeiras aparecem nas fotografias intituladas: "Aparelhos; Carrossel; Joguinho - apanhar o lenço; Joguinho - corrida com batatas; Joguinho - apanhar o lenço; Joguinho - o pulo do canguru; Voley-ball; Balanço; Passo de gigante; Escorregadouro; Jogo de construçăo; Gangorra; Pingue-pongue; Tanque de areia; Jogos tranqüilos; Jogo de damas e Jogo de domino".

Atividades culturais, artísticas e artesanais estáo em fotos como: "Teatrinho; Desenho; Marcenaria; Jardinagem; Modelagem; Trabalhos manuais (bordados, tapeçaria); Exposiçāo do trabalho das crianças; Valsa; Dança indigena; Recorte de gravuras; Bailado da Nau Catarineta; Leitura; Biblioteca; Prateleira de livros; Reuniáo da diretoria do clube; Eleiçăo - votaçăo e Eleiçăo - votantes." (9)

Em julho de 1937, as crianças do Parque Infantil Pedro II apresentaram o bailado da Marujada durante as programaçós de encerramento do Congresso da Lingua Nacional Cantada idealizado por Mário de Andrade e promovido pelo Departamento de Cultura. O congresso reuniu especialistas em música e linguística para a fixaçăo de normas de pronúncia em "lingua nacional" para o canto erudito e ó teatro. $O$ congresso foi um dos momentos de maior expressáo do esforço de Mário em promover, através do Departamento de Cultura, as bases para a "nacionalizaçăo" da arte e da cultura no Brasil. Com este mesmo objetivo, as crianças do Pedro II aprenderam os bailados da Marujada e o da Nau Catarineta, fotografados por Benedito Duarte, para que as danças folcloricas brasileiras pudessem ser preservadas em nossa tradição cultural. Ainda com o mesmo objetivo, as crianças serviram de informantes para que fossem registradas cantigas, brincadeiras e danças tradicionais que aprendiam em casa com seus pais e avós.

8 Idem.

9 A colechto de fotografias de Benedito Duarte encontra-se no Setor de Iconografia do Departamento do Patrimonio Histórico da Secretaria de Cultura da Prefeitura Municjpal de Sāo Paulo.

Rev. Inst. Est. Bras., SP, 36:263-270, 1994 
Mário de Andrade guardou com ele centenas de desenhos feitos pelas crianças dos parques infantis por ocasiáo dos concursos promovidos pela Biblioteca Infantil do Departamento de Cultura. No verso de cada desenho, encontramos o nome, a idade da criança, a nacionalidade dos pais e o parque que ela frequentava. $O$ interesse de Mário por esses desenhos se deve talvez ao fato de que o processo criativo infantil constituiu uma de suas preocupaçoes. Ou ainda, o interesse resultou de sua busca constante de elementos que pudessem indicar os caminhos da "nacionalizaçăo" da cultura e da arte no Brasil. O registro da nacionalidade dos pais no verso dos desenhos indica a preocupaçăo iem desvendar o ambiente cultural da criança. Como portadora de tradiçoes culturais, a criança certamente expressaria na criaçăo dela (no caso, o desenho) os traços particulares dessa tradiçăo. A compreensão deste processo de relaçăo entre arte e cultura seria portanto mais uma referencia na busca da afirmaçăo das características "nacionais" da cultura brasileira.

A safda de Mário de Andrade do Departamento de Cultura se deu em funçăo das mudanças políticas ocorridas na Prefeitura de Sáo Paulo depois do golpe do Estado Novo de Getúlio Vargas. Enquanto Armando de Salles Oliveira, Fábio Prado e Paulo Duarte seguiram para o exflio, Mário deixou a Prefeitura e mudou-se para o Rio de Janeiro. Foi substituido por Francisco Pati, escolhido pelo novo prefeito Prestes Maia. Até o último momento, o diretor garantiu a preservaçăo do Departamento. Numa atitude talvez ingênua demais, escreveu ao Ministro Capanema solicitando - e nāo obtendo resposta - intervençăo dele, ou até do próprio Presidente, junto ao novo Prefeito de Sáo Paulo, para que conseguisse "se náo a salvaçăo, pelo menos a garantia de um órgåo que tenho a conviç̧ăo de ser admirável, que é utilíssimo ao Brasil, e em tres anos conseguiu larga divulgaçăo e respeito internacional." (10)

Mas muito pouco se preservou do Departamento de Cultura depois da saida de Mário de Andrade. Sem apoio do novo governo municipal, quase todos os projetos iniciados foram interrompidos. Alguns sobreviveram precariamente, como e o caso da Discoteca Pública, mantida com heroísmo por Oneyda Alvarenda ainda por muitos anos. E hoje, quando olhamos para este órgá municipal, vemos com inevitável admiraçáo o pioneirismo dos trabalhos ali iniciados. Mas é tambem inevitável o incomodo diante de um projeto cultural em tantos aspectos claramente progressista concretizado num ambiente politico bastante autoritário e conservador. O Departamento de Cultura, através de um amplo programa educativo, realmente criou mecanismos institucionais de vulgarizaçăo da arte e da cultura. No entanto, nđ̃o podemos esquecer que isto se deu nos anos imediatamente anteriores à implantaçáo da ditadura do Estado Novo em 1937. As discussర́es apenas se iniciaram. Certamente, ainda há muito o que pensar.

10 - Carta de Mário de Andrade a Gustavo Capanema, Sáo Paulo, 10/5/1938. Citado por SCHWARTZMAN, Simon et al. Tempas de Capanema. Rio de Janeiro, Paz e Terra/Sao
Paulo, Edusp, 1984. p. 368-9. 